\title{
IMPACT OF DIFFERENT VARIABLES ON ACADEMIC PERFORMANCE \& LEARNING
}

\author{
Momna Shahzad $\bowtie$; NUST Business School, National University of Sciences and Technology \\ (NUST), Pakistan \\ Tamseel Asim; NUST Business School, National University of Sciences and Technology (NUST), \\ Pakistan
}

Abbira Hassan; English Department, Islamia University of Bahawalpur, Pakistan

\begin{abstract}
Academic performance and learning is a widely studied research area. It incorporates various aspects and can be measured through a plethora of dimensions including the performance of students in standardized tests, their grades and GPA in university courses, the ra te of graduation, the rate of class participation, entrance tests of colleges, the overall class performance of students and so on. In this research we have taken blogging, reading, writing and communication skills as the independent variables on which the academic performance and learning is dependent. The population for this quantitative research was the students of National University of Science and Technology, Pakistan.
\end{abstract}

Keywords: Quantitative Research, Academic Performance and Learning, Blogging, Reading, Writing, Communication Skills.

$\triangle$ momna.m20nbs@student.nust.edu.pk

Citation: Shahzad. M., Asim, T., \& Hassan, A. (2021). Impact of different variables on academic performance \& learning. Social Sciences, Humanities and Education Journal (SHE Journal) , 2(2), 112 - 131. DOI: $10.25273 /$ she.v2i2.9230

\section{$((c)) B Y-N C-S A$}

Published by Universitas PGRI Madiun. This work is licensed under the Creative Commons Attribution-NonCommercialShareAlike 4.0 International License. 


\section{INTRODUCTION}

Academic Performance and learning, of students has been a significant area of interest in the field of academia and has long been studied by different researchers. Academic performance incorporates various aspects and can be measured through a plethora of dimensions including the performance of students in standardized tests, their grades and GPA in university courses, the rate of graduation, the rate of class participation, entrance tests of colleges, the overall class performance of students and so on. The importance of academic performance can be gauged from the fact that the better the learning and performance of students in academics, the higher the quality of graduates that colleges and universities will be producing. These students with bright academic record would then enter the future workforce. Therefore, not only the employment rate would improve but these students would also add value to the organizations they join or might invest their learnings and knowledge into starting their own business. It is crucial to consider the factors that actually affect the academic performance of students which range from various economic factors to social factors to psychological factors to environmental factors and even personal factors. Hence, the motivational factors that lead to better academic performance are also different and the activities and skills that are conducive to a good academic performance is also questioned by different researchers.

\section{Research Objective}

The objective of our research is to actually determine the impact of various underlying activities on the academic performance of students. We have identified four key activities including online blogging, pleasure reading, writing and communication skills of students and will be conducting an indepth analysis of the relationship between these activities and students' academic performance.

\section{Literature Review}

Our dependent variable is "Academic Performance" of students.

As the instruction of education and academic performance are not tangible so their measurement is quite hard since they bring about the type of change of information, fundamental abilities and changes of conduct among students (Tsinidou, Gerogiannis, \& Fitsilis, 2010). There is a scope of elements that effect on the performance quality of the students (Waters and Marzano, 2006).

Social Networking Sites (SNS's) can be utilized as learning applications to assist students with coordinating and engaging. There are numerous investigations to exhibit a significant effect of SNSs on the academic performance of the students. Involving and inspiring students permits them to use intelligent instruction games and virtual learning conditions. This habit gives them more association through inclusion by social networking, which connects with the active learning of the students (Franlin,2011). Harb and ElShaarawi (2006) found that the main factor with constructive outcome on students' exhibition is dependent on their English competency skills. In the event that the understudies have solid relational abilities and have solid hold on English, it expands the presentation of 
the understudies. The presentation and performance of the students are highly influenced by their communication skills and their solid hold on English.

Therefore, there are multiple factors affecting academic performance and we aim to figure out some of these through our research.

\section{Blogging}

One of the independent variables that we will be considering for our research is "blogging".

Word blog is taken from weblog. When someone shares their ideas and opinions on the social platform through writing that is weblog. According to Puschmann, blog came under spotlight since its development in late 1990s. Writing for a blog has recently gained interest among EFL instructors and students as another way to deal with classroom teaching methods for writing.

Online journals place an extraordinary spotlight on students' composing mechanics, empower them, and give them more prominent classroom composing elements. Publishing content to a blog is a brilliant path for students to speak with each other in a socially based setting through innovation (Penrod, 2007; Boling, 2008; Higginson, 2009; Stanley, 2013). The research has uncovered that blogs play an extensive part in improving student reflection, classroom exchange and informal communication also known as social networking (Hartley,2007). Henceforth, the literature review shows a positive relationship between blogging and academic performance and we aim to prove that through our research.

\section{Reading}

The next independent variable that we will be considering is pleasure "reading".

As indicated by Clark and Rumbold (2006), reading for the sake of pleasure was characterized as reading done under fully expecting the fulfillment it would bring or proceeding with required reading in light of the fact that the reader found the topic intriguing. Pleasure reading is an individual encounter that "ordinarily includes materials that mirror our own decision, at a time and place that suits us"(Clark \& Rumbold, 2006, p. 6). "By independent reading students acquire an abundance of foundation information about a wide range of things, come to get story and genuine designs, retain the basics of English language structure, and persistently extend their vocabularies" (Strauss, 2014, para. 9). Pleasure reading would clearly affect understanding cognizance, language, and jargon; notwithstanding, the effect it has on the academic achievement in other core subjects couldn't be downplayed. Reading gave foundation information and cognizance abilities important for students' accomplishment in technical studies, science, and history (Sellgren, 2013). Henceforth, the literature review indicates a positive relationship between reading and academic performance, and we will try to prove that through our research.

\section{Writing (skills and habit)}

The third independent variable under consideration is "writing".

Writing is a term defined by various experts. According to White (1986), "writing is the process of expressing 
ideas, information, knowledge or experience and understand the writing to acquire the knowledge or some information to share and learn (p.10)". Moreover, according to Nunan (2003), "writing is an intellectual activity of finding the ideas and thinking about the way to express and arrange them into a statement and paragraph that is clear to be understood by people (p.88)". Writing has a direct link with academic performance and learning, so it is a capability every student must possess. Writing skills equip the students with necessary communication and learning skills. It also makes the learning and thinking power strong, visible and permanent. It fosters the students' ability to explain and refine their ideas to others and themselves. "Writing is, in fact, one of the best tools for learning any material because it activates thinking" (Zemelman et al., 1998, p.63). As writing is viewed this way by many in academia so it has led us to testify that writing along with skills and habit provide maximum contribution to student's academic and learning performance and therefore, we intend to prove this by our quantitative research as well.

\section{Communication Skills}

The last independent variable that we will be analyzing is "communication skills".

The word communication is derived from a Latin word 'communicare' which means to share or to participate. According to Leland Brown, "communication is the transmission and interchange of facts, ideas, feelings or course of action". The ability to communicate effectively is essential for students. The experts say that the better the students are at communication the better their academic life will be. Effective communication is regarded as a vital matter to strengthen the teacher student relation (FrymierA, 2007).

Anderson views communication as a dynamic process in which a person consciously or unconsciously affects the cognition of another person through materials or agencies used in symbolic ways. In the same vein, Ndoloi (1998) contends that communication is the transactional process concerned with the creation, transmission, interpretation and use of information. The knowledge and skills include those which are concerned with problem-solving, information and communication technology, administration and management, science and technology, research, and languages (Komba, 2012). Such knowledge and skills can be acquired in schools, institutes, colleges, and universities through a given medium of instruction which facilitates communication among the involved parties. According to Albert Mehrabian "The way people take information during communication is 55\% Body Language compared to 38\% Voice and Tone and only $7 \%$ through Words."

Effective communication encompasses the 4 main points: choice of best communication channel, enough technical knowledge to use that channel properly and understanding the target audience to present information in appropriate manner, ability to grasp the response received from others.

Students at all levels of education must be able to communicate effectively, students lacking these skills have impact 
on their academic performance, they are at the higher risk of falling behind their peers or sometimes withdrawn at various level in their academic life.

Communication skills help the students gain confidence and the power to fearlessly express them, so it affects students' academic life and eventually the academic success. (Bee, 2012) focused on the importance of communication and its effect on classroom management, and teacherstudent interaction. Therefore, there seems to be a positive relationship between communication skills and academic performance and hence our aim is to prove this relationship through our research.

\section{Research methodology}

\section{i. Research design}

We wanted to see the impact of different variables like Blogging, reading, writing and communication skills on the Academic performance and learning of students. For this purpose, we opted for quantitative research design to measure their affects as it fit perfectly for our research due to its focus on aspects like who, where, when, what instead of how. For measuring these variables, we made a questionnaire/survey consisting of various questions that specifically measures their impact on the academic performance and learning of students over the Likert scale ranging from 1 till 5 . These questionnaires were distributed among the students and their responses were collected.

\section{ii. Population}

For us it wasn't feasible to get the responses of students across all the educational institutes for the feasibility we opted Convenience Sampling (NonProbability Sampling) and consider the students of two NUST schools that are National Business School and School of Social Sciences and Humanities.

Our population consisted of Students enrolled in various bachelor's and Master programs with an age group ranging from 15-18 to 27 and above. Considering all the students in various semesters ranging from 1st till 8th semester for the bachelor students and 1st to 4th semesters for the students enrolled in Masters. The responses collected included both male and female students.

\section{iii. Sample size}

For us it wasn't feasible to get the responses of students across all the educational institutes so for the feasibility we opted for Convenience Sampling (Non-Probability Sampling) and consider the students of two NUST schools that are National Business School and School of Social Sciences and Humanities.

Our population consisted of Students enrolled in various bachelors and Master Programs with an age group ranging from $15-18$ to 27 and above. Considering all the students in various semesters ranging from 1st till 8th semester for the bachelor students and $1^{\text {st }}$ to $4^{\text {th }}$ semesters for the students enrolled in Masters. The responses collected included both male and female students.

\section{iv. Data collection method}

For the data collection we distributed our designed questionnaire that contained data for the demographics and 19 questions collectively which was 
categorized for measuring each variable separately. 4 questions for measuring Blogging, 3 questions for Reading, 5 questions for Writing, 4 questions for Communication and 3 questions for Academic Performance and Learning.

These questionnaires were distributed among the students in classes of NBS and S3H which were enrolled in both bachelors and master's programs and their responses were collected. As it wasn't possible for us to get the responses from all the students of NUST thus, we selected two schools for the convenience sampling. We got 88 responses from them. Their responses were measured by using Likert Scale for each variable ranging as 1 for Strongly Disagree, 2 for Disagree, 3 for Neutral, 4 for Agree and 5 for Strongly Agree. Later the data collected from these questionnaires were analyzed by using SPSS tools like descriptive analysis, regression analysis, correlation analysis, testing of the hypothesis, reliability analysis as well as normality analysis.

\section{Theoretical Framework}

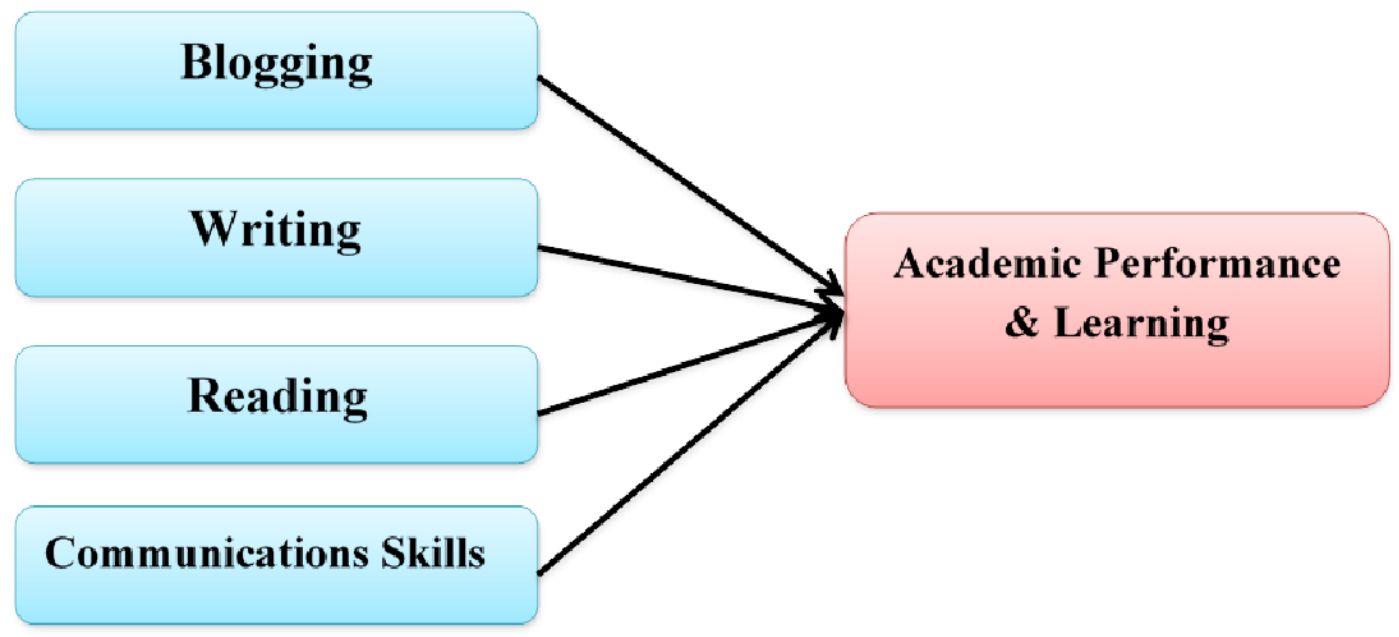

Figure 1: The Independent and dependent variables in the research.

\section{Hypothesis Development:}

H1: There is a significant positive relationship between blogging on different social media platforms and academic performance and learning of students.

H2: There is a significant positive relationship between reading and academic performance and learning of students.
H3: There is a significant positive relationship between the writing habit and skills of students and their academic performance and learning.

H4: There is a significant positive relationship between the communication skills of students and their academic performance and learning.

\section{Descriptive Analysis:}

Firstly, descriptive analysis has been done with respect to the demographics of the respondents 
of our survey. These demographics include their gender, age, their program of study at NUST, the department within NUST that they belong to and lastly the semester they are currently enrolled in.

\section{Frequencies}

Table 1 shows the descriptive analysis on the bases of 'Gender':

\section{Gender}

\begin{tabular}{lll|l|l|l} 
& & Frequency & Percent & \multicolumn{1}{|l}{$\begin{array}{l}\text { Valid } \\
\text { Percent }\end{array}$} & $\begin{array}{l}\text { Cumulative } \\
\text { Percent }\end{array}$ \\
\hline Valid & Male & 32 & 36.4 & 36.4 & 36.4 \\
\cline { 2 - 6 } & Female & 56 & 63.6 & 63.6 & 100.0 \\
\cline { 2 - 6 } & Total & 88 & 100.0 & 100.0 & \\
\hline
\end{tabular}

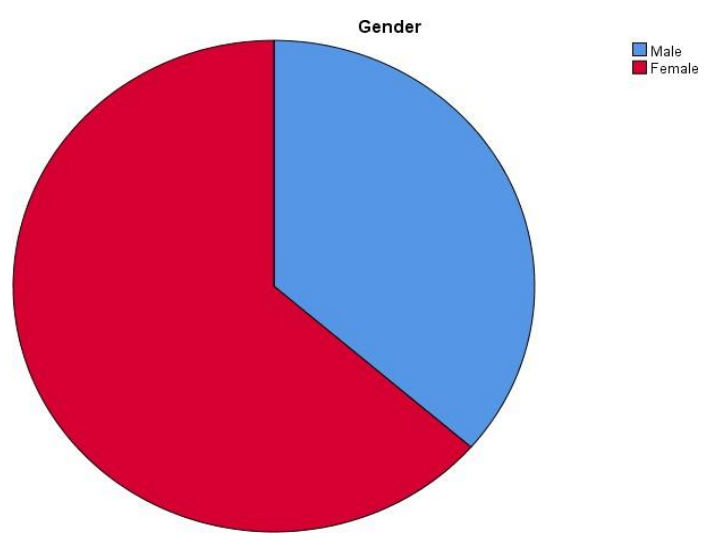

Chart 1: Pie chart showing descriptive analysis of Gender.

The table 1 above shows that out of the 88 respondents of our survey sample size, 32 were male and 56 were female. Hence, it can be seen that the responses were more female-dominated, hence

Table 2 shows the descriptive analysis on the bases of 'Age':

\begin{tabular}{ll|l|l|l}
\multicolumn{2}{l}{ Age } \\
Frequency
\end{tabular}




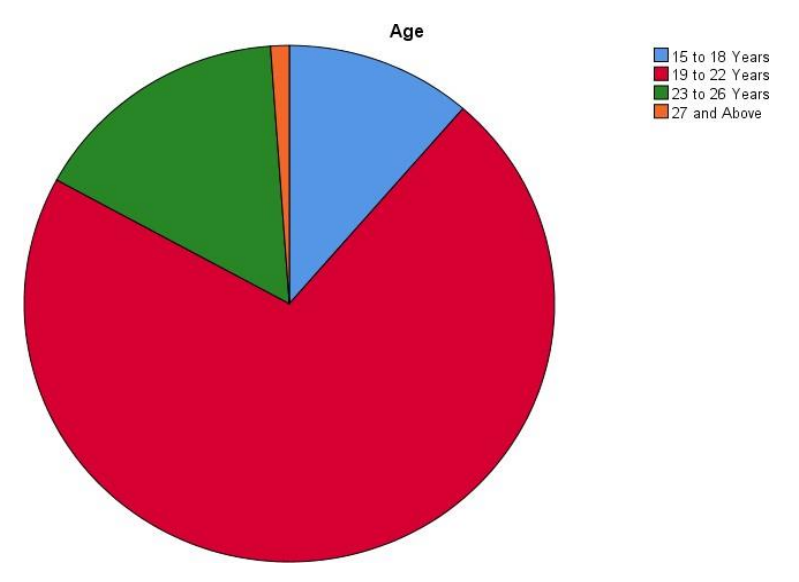

Chart 2: Pie chart showing descriptive analysis of Age.

Considering that the students enrolled at NUST belong to different age groups; some being younger than the average while others being older than the average. Hence, we provided our respondents options of multiple age groups in the survey and from the results shown in table above, we can determine that the majority of the sample students; specifically, 63 respondents belonged to the age group of 19-22 years which is generally the average age of university students. Apart from that, 10 respondents belonged to the age group of 15-18 years, 14 students belong to the age cohort of 23-26 years while only 1 of our respondents belonged to the age group of 27 and above. These results are also represented above in the form of a pie-chart for a quick assessment.

Table 3 shows the descriptive analysis on the bases of 'Program':

Program

\begin{tabular}{llcccc}
\hline \multicolumn{2}{c}{ Frequency } & & Percent & Valid & Cumulative \\
& & & Percent & Percent \\
\hline Valid & BS & 80 & 90.9 & 90.9 & 90.9 \\
\cline { 2 - 5 } & Masters & 8 & 9.1 & 9.1 & 100.0 \\
\cline { 2 - 5 } & Total & 88 & 100.0 & 100.0 & \\
\hline & & & & & \\
\hline
\end{tabular}

Chart 3: Pie chart showing descriptive analysis of Program. 
Since the no. of students enrolled in bachelor's programs at NUST is much greater than the master's students hence while we did distributed surveys to students randomly, it occurred such that out of those 88 respondents, 80 were enrolled in some program at the bachelor's level while only 8 of them belonged to a Master's Program.

Table 4 shows the descriptive analysis on the bases of 'Department':

Department

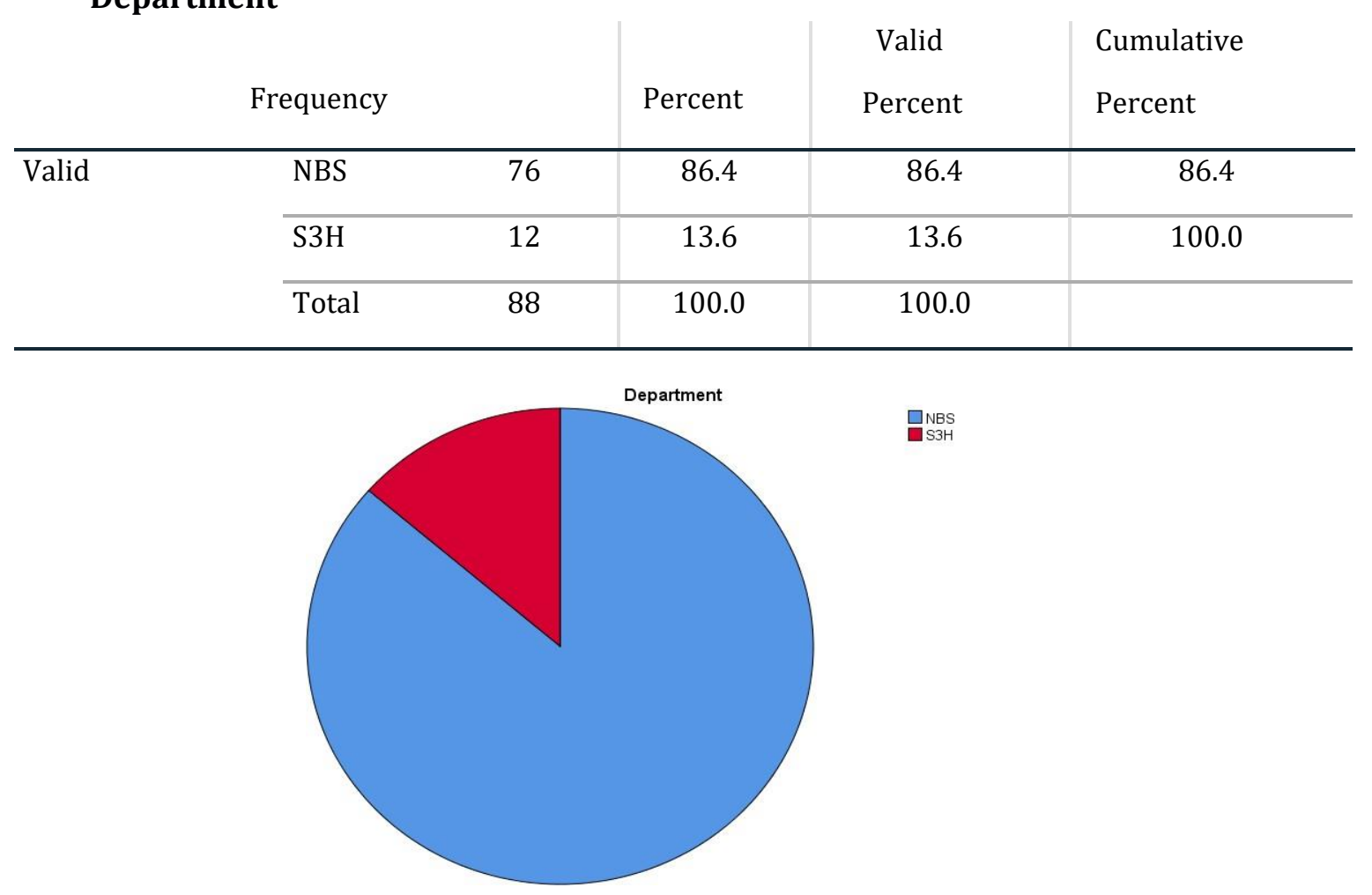

Chart 4: Pie chart showing descriptive analysis of Department.

Being students of students of NUST Business School (NBS) ourselves, we did convenience sampling and chose to conduct survey only on students of NBS and $\mathrm{S} 3 \mathrm{H}$ (School of Social Sciences and
Humanities), hence out of the 88 respondents, 76 were from NBS while only 12 belonged to $\mathrm{S} 3 \mathrm{H}$.

Table 5 shows the descriptive analysis on the bases of 'Department':

Semester

\begin{tabular}{|c|c|c|c|c|c|}
\hline & \multicolumn{2}{|c|}{ Frequency } & Percent & $\begin{array}{c}\text { Valid } \\
\text { Percent }\end{array}$ & $\begin{array}{c}\text { Cumulative } \\
\text { Percent }\end{array}$ \\
\hline \multirow[t]{3}{*}{ Valid } & 1.00 & 22 & 25.0 & 25.0 & 25.0 \\
\hline & 2.00 & 18 & 20.5 & 20.5 & 45.5 \\
\hline & 3.00 & 9 & 10.2 & 10.2 & 55.7 \\
\hline
\end{tabular}




\begin{tabular}{c|c|c|c|c}
\hline 4.00 & 3 & 3.4 & 3.4 & 59.1 \\
\hline 5.00 & 4 & 4.5 & 4.5 & 63.6 \\
\hline 7.00 & 3 & 3.4 & 3.4 & 67.0 \\
\hline Total & 29 & 33.0 & 33.0 & 100.0 \\
\hline & 88 & 100.0 & 100.0 & \\
\hline
\end{tabular}

Chart 5: Pie chart showing descriptive analysis of Semester.

Out of the 88 respondents, 22 students were enrolled in the $1^{\text {st }}$ semester, 18 students in the $2^{\text {nd }}$ semester, 9 students in the $3^{\text {rd }}$ semester, 3 students in the $4^{\text {th }}$ semester, 4 students in the $5^{\text {th }}$ semester, 3 students in the $7^{\text {th }}$ semester and 29 students in the last i.e., $8^{\text {th }}$ semester. Hence, it can be concluded from this, that the majority of our respondents were final year bachelor's students who are about to graduate.

\section{Descriptive}

Table 6: Descriptive Statistics

\begin{tabular}{lc|c|c|c|c}
$\mathrm{N}$ & & Minimum & Maximum & Mean & Std. Deviation \\
\hline Blogging & 88 & 1.75 & 5.00 & 3.8068 & .66817 \\
\hline Reading & 88 & 1.00 & 5.00 & 3.8030 & .82990 \\
\hline Writing & 88 & 1.00 & 5.00 & 3.9000 & .71245 \\
\hline C_Skills & 88 & 1.50 & 5.00 & 3.8068 & .75117 \\
\hline AP & 88 & 1.00 & 5.00 & 3.4583 & .76031 \\
\hline Valid N (list wise) & 88 & & & & \\
\hline
\end{tabular}

We had run the 'descriptive' test for the responses to questions of all our 
independent as well as dependent variable and the mean values for each of the variable is greater than 3 which implies that the average responses were more inclined towards the agreed side on the Likert scale. E.g., the mean for the independent variable of blogging is 3.81 which indicate that people tend to agree about the effect of blogging on academic performance and learning of students. The standard deviation of blogging is also very small i.e., 0.668 hence it means that the values of responses lie near the mean. Similarly, the mean value for reading variable is also 3.80 representing the students' agreeability to the fact that pleasure reading does have a direct impact on academic performance. The standard deviation for this is also quite small i.e., 0.83 hence there is not much variation in the responses of students. Then, the mean value for questions related to the independent variable of Writing Skills is 3.9 again implying that the responses tend towards the agreed side with very little standard deviation of 0.71 . Lastly, the mean for the independent variable of communication skills is 3.81 with standard deviation of 0.74 , therefore the conclusion is unanimous that most students agree about the positive relationship with academic performance and

Table 7: Regression Analysis:

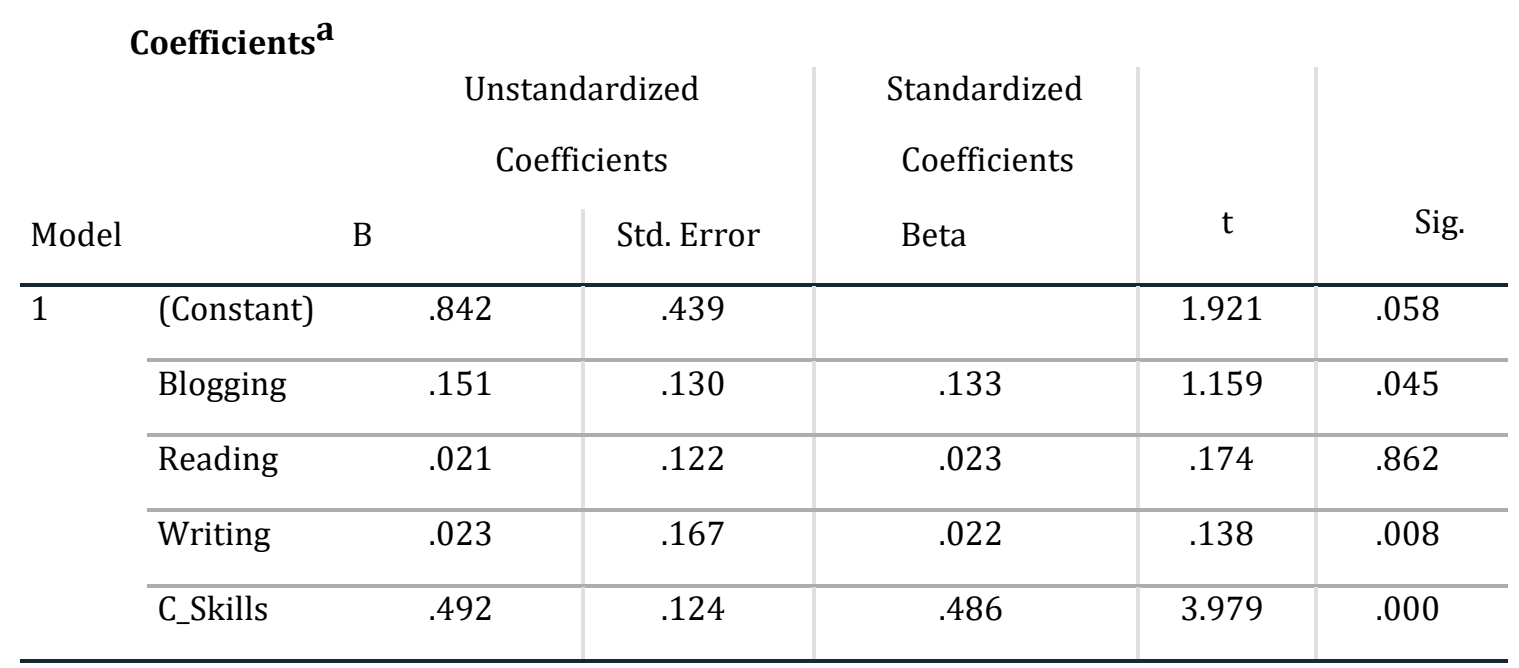

a. Dependent Variable: AP

\section{Interpretations}

$\mathrm{X} 1=$ Blogging, $\quad \mathrm{X} 2=$ =Reading, $\quad \mathrm{X} 3=$ Writing, $X 4=$ Communication Skills and $\mathrm{Y}=$ AcademicPerformance

\section{Multiple Regression line:}

$$
\begin{aligned}
& \mathrm{Y}=0.842+0.151 \mathrm{X} 1+0.021 \mathrm{X} 2 \\
& +0.023 \mathrm{X} 3+0.492 \mathrm{X} 4
\end{aligned}
$$

Academic Performance $=0.842+$ 0.151(Blogging) + 0.021(Reading)

$+\quad 0.023$ (Writing)

0.492(Communication Skills)

\section{Relationships:}

I. Relationship between blogging and Academic Performance and Learning is positive as $B=0.151$ 
which implies that the more the students engage in online blogging and journaling activities, the better the impact on their grades or GPA.

II. Relationship between reading and Academic Performance and Learning is positive as $\mathrm{B}=0.021$, hence it means that those students who have pleasure reading as their hobby, have a better academic performance.

III. Relationship between writing and Academic Performance and Learning is positive as $\mathrm{B}=0.023$, therefore it indicates that students with better writing skills will also have a better academic performance.

IV. Relationship between communication skills and Academic Performance and Learning is positive as $\mathrm{B}=0.492$, which again implies that students with strong communication skills and presentation skills would have a good academic performance.

\section{Hypothesis Testing:}

\section{Step\#1: Hypothesis Formulation}

Null Hypothesis:

$\mathrm{H}^{\circ} 1$ : There is no significant relationship between blogging on different social media platforms and academic performance and learning of students.

$\mathrm{H}^{\circ} 2$ : There is no significant relationship between reading and academic performance and learning of students.

$\mathrm{H}^{\circ} 3$ : There is no significant relationship between the writing habit and skills of students and their academic performance and learning.

$\mathrm{H}^{\circ} 4$ : There is no significant relationship between the communication skills of students and their academic performance and learning.

\section{Alternative Hypothesis:}

H1: There is a significant positive relationship between blogging on different social media platforms and academic performance and learning of students.

H2: There is a significant positive relationship between reading and academic performance and learning of students.

H3: There is a significant positive relationship between the writing habit and skills of students and their academic performance and learning.

H4: There is a significant positive relationship between the communication skills of students and their academic performance and learning.

\section{Interpretations:}

Step\#2: Level of significance:

Alpha $=5 \%$

\section{Step\#3: Rejection Rule:}

$\mathrm{H}^{\circ} 1, \mathrm{H}^{\circ} 2 \mathrm{H}^{\circ} 3$ and $\mathrm{H}^{\circ} 4$ will be rejected if Sig. Level is 0.05 or less.

\section{Step\#4: Conclusion:}

The Sig. level of blogging (sig. = 0.045 ) is less than 0.05 , hence the null hypothesis $\left(\mathrm{H}^{\circ} 1\right)$ is rejected, and it can be concluded that there is a significant positive relationship between blogging on different social media platforms and academic performance and learning of students. Hence the data collected from our respondents also coincides with our research about blogging. 
According to Aydin (2014), blogging considerably improves the learning capacity of students. Therefore, the more students who blog, the better their academic performance becomes.

While the Sig. level of reading (sig. $=0.862$ ) is more than 0.05 therefore the null hypothesis $\left(\mathrm{H}^{\circ} 2\right)$ is accepted. According to the above interpretation it can be said that pleasure reading has an insignificant relationship with the academic performance. This could be because there are other more important factors that affect academic performance, or it could be due to the fact that our sample consisted majority of students from NUST business School instead of the School of Social Sciences and Humanities. Hence, business school students tend to do less pleasure reading than the humanities students, and therefore they might not agree towards the impact of such reading on academic performance. Direct research into the effect of reading for pleasure on adult literacy [and hence academic performance] is scarce. This is perhaps because reading for pleasure is less quantifiable than other influences on a non-reading adult's quality of life (Christina Clark and Kate Rumbold, 2006).

Similarly, the significance level of writing (sig. $=0.008$ ) is also less than 0.05, hence the null hypothesis $\left(\mathrm{H}^{\circ} 3\right)$ will be rejected. Therefore, the alternative hypothesis will be accepted that there is a significant positive relationship between the writing habit and skills of students and their academic performance and learning. This was also proved by our research and literature review. As Applebee and Langer (2006, p. 1) states that writing help students give voice to their thoughts fully which in turn improves their comprehension skills; this ultimately helps them to evolve on academic terms.

Lastly, the significance level for the independent variable of communication skills (sig. $=0.000$ ) is less than 0.05 therefore the null hypothesis $\left(\mathrm{H}^{\circ} 4\right)$ is rejected. Hence, it can be said that there is a significant positive relationship between the communication skills of students and their academic performance and learning. In academic terms, students who show higher level of willingness to communicate as more likely to participate in classroom activities and have better chances to actually perform well in a number of subjects as compared to those who show low willingness level to communicate with fellow students (Cho, Geri, Davidson \& Ingraffea, 2007). Therefore, such students have better academic performance. 
Table 8: Multi-Collinearity Test (Correlation Analysis):

\section{Correlations}

\begin{tabular}{|c|c|c|c|c|c|c|}
\hline Blogging & & & Reading & Writing & C_Skills & AP \\
\hline \multirow[t]{3}{*}{ Blogging } & Pearson Correlation & 1 & $.518^{* *}$ & $.567^{* *}$ & $.533^{* *}$ & $.416^{* *}$ \\
\hline & Sig. (2-tailed) & & .000 & .000 & .000 & .000 \\
\hline & $\mathrm{N}$ & 88 & 88 & 88 & 88 & 88 \\
\hline \multirow[t]{3}{*}{ Reading } & Pearson Correlation & $.518^{* *}$ & 1 & $.724^{* *}$ & $.398^{* *}$ & $.301^{* *}$ \\
\hline & Sig. (2-tailed) & .000 & & .000 & .000 & .004 \\
\hline & $\mathrm{N}$ & 88 & 88 & 88 & 88 & 88 \\
\hline \multirow[t]{3}{*}{ Writing } & Pearson Correlation & $.567^{* *}$ & $.724^{* *}$ & 1 & $.644^{* *}$ & $.527^{* *}$ \\
\hline & Sig. (2-tailed) & .000 & .000 & & .000 & .000 \\
\hline & $\mathrm{N}$ & 88 & 88 & 88 & 88 & 88 \\
\hline \multirow[t]{2}{*}{ C_Skills } & Pearson Correlation & $.533^{* *}$ & $.398^{* *}$ & $.644^{* *}$ & 1 & $.779^{* *}$ \\
\hline & Sig. (2-tailed) & .000 & .000 & .000 & & .000 \\
\hline $\mathrm{N}$ & & 88 & 88 & 88 & 88 & 88 \\
\hline \multirow[t]{3}{*}{ AP } & Pearson Correlation & $.416^{* *}$ & $.301^{* *}$ & $.527^{* *}$ & $.779^{* *}$ & 1 \\
\hline & Sig. (2-tailed) & .000 & .004 & .000 & .000 & \\
\hline & $\mathrm{N}$ & 88 & 88 & 88 & 88 & 88 \\
\hline
\end{tabular}

**. Correlation is significant at the 0.01 level (2-tailed).

Firstly, we will analyze the test of multi-collinearity to determine if there is any sort of inter- dependence between the independent variables of blogging, reading, writing and communication skills. The Pearson Correlation value between Blogging and Reading is 0.518 is a very nominal and insignificant value and is less than 0.8 , hence we can conclude that these both variables are independent of each other and the questions asked in our survey related to both these variables are not inter-related to each other. Similarly, the Pearson correlation value between blogging and writing is 0.567 which is again a small and insignificant value, hence there is no issue of multi- collinearity between these two variables either. The value of correlation between blogging and communication skills 5.33 which is also an insignificant figure and implies that both these variables and the questions asked in survey related to these are different from each other. If we see the correlation figure between reading and writing variable, it is 0.724 which is higher than the rest of the correlation values but since it is lower than 0.8 , we can conclude there to be no issue of multi-collinearity. Then, the Pearson 
correlation value between the independent variable of Reading and Communication skills is 0.398 which is again a very small and negligible figure, therefore we can say that these two variables are entirely different from each other. Moving forward, if we analyze the correlation value between writing and communication skills, it is 0.644 which is again a small value and indicates that both these variables are independent of each other. Henceforth, it can be concluded that all of the independent variables and the questions and dimensions used to assess them, are different from each other.

Now, we will be analyzing the strength of the relationship of each of the independent variable with the dependent variable of Academic Performance and Learning. First of all, from the above table, we conclude that the $R$ value of 0.416 between blogging and academic performance indicates that there is a weak positive relationship between the two, at confidence level of $p=0.01$. The $R$ value of 0.301 between pleasure reading and academic performance reflects that there is again a weak positive relationship between them, at $p=0.01$. Similarly, the R value of 0.527 between writing and academic

\section{Blogging}

Table 9: Reliability Analysis of Blogging Reliability Statistics

Cronbach's Alpha performance and learning of students reflects that there is a positive relationship between them, at $\mathrm{p}=0.01$. Lastly, the $R$ value of 0.779 at $p=0.01$ indicates that there is a very strong positive relationship between the communication skills of students and their overall academic performance and learning.

\section{Reliability Analysis}

Reliability Analysis was conducted by computing the Cronbach's Alpha for each of the independent and dependent variable separately. This was done in an attempt to gauge the reliability and internal consistency of the questions asked in the survey related to each of the variables, or in other words to assess the accuracy and consistency of the dimensions used to assess these variables. A general accepted rule is that Cronbach Alpha of 0.6-0.7 indicates an acceptable level of reliability, and 0.8 or greater a very good level. However, values higher than 0.95 are not necessarily good, since they might be an indication of redundancy [of questions] (Hulin, Netemeyer, and Cudeck, 2001).
The Cronbach Alpha for the independent variable of students 'Blogging' on social media and other online forums is 0.679 which is greater than 0.6 . Hence it is acceptable, and we can conclude that the range of questions asked from the respondents related to blogging were 
reliable to infer the relationship with the

performance.

dependent variable of academic

\section{Reading}

Table 10: Reliability Analysis of Reading

\section{Reliability Statistics}

Cronbach's Alpha

$\mathrm{N}$ of Items

.779

The independent variable of pleasure reading done by students has a Cronbach's Alpha of 0.779 which is greater than 0.6 and is also higher than that of the blogging variable. Therefore, we can say that the parameters and

\section{Writing}

Table 11: Reliability Analysis of Writing

\section{Reliability Statistics}

Cronbach's Alpha questions used to assess the reading variable which were three in number, are reliable and can be used to determine the relationship with academic performance.

$$
.812
$$

The Cronbach's Alpha for the independent variable of writing skills and habit of students, is 0.812 and can be considered very good since it is greater than 0.8. The no. of questions used to assess this variable were 5 in number
$\mathrm{N}$ of Items

\section{Communication Skills}

Table 12: Reliability Analysis of Communication Skills

\section{Reliability Statistics}

$$
\text { Cronbach's Alpha }
$$

$\mathrm{N}$ of Items

\section{.802}

4

The independent variable of Communication skills of students is 0.802 which is again greater than 0.8 , and it can be deemed that these dimensions were reliable give us a fair idea about the relationship between writing and academic performance. 
variable were 4 in number and it can be

were sufficient and reliable. concluded that the dimensions used

\section{Academic Performance and Learning}

Table 13: Reliability Analysis of Academic Performance and Learning

Reliability Statistics

Cronbach's Alpha

$\mathrm{N}$ of Items

Table 14: Normality Analysis

Descriptive Statistics

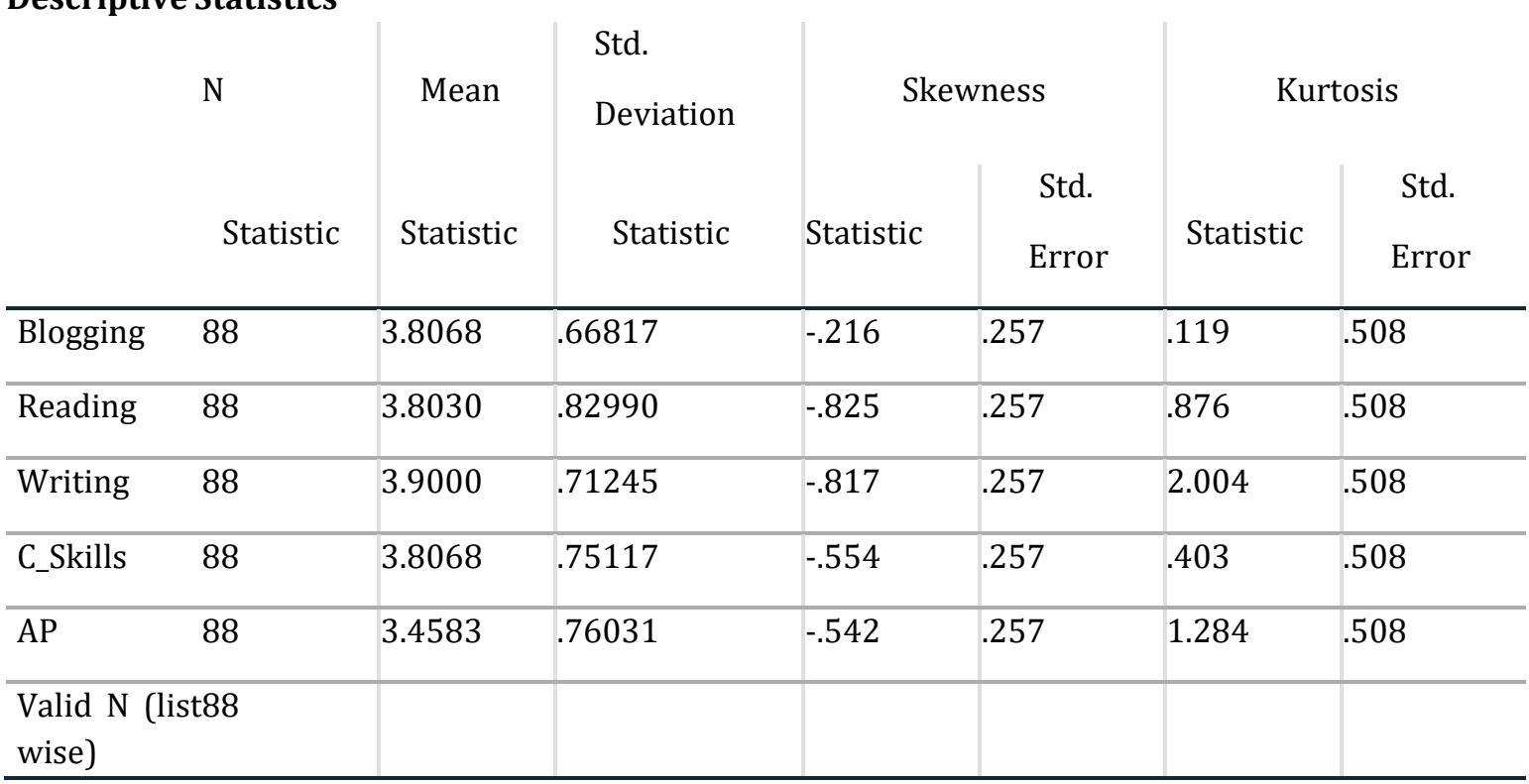

The Cronbach's Alpha for the dependent variable of academic performance and learning is 0.837 which is greater than

\section{Normality Analysis}

We have conducted normality analysis to determine whether the data we have collected through the responses of our survey, lie within the domain of normal distribution. For this, we will be focusing on the statistic of Skewness and Kurtosis. "Acceptable values of skewness fall between -3 and +3 " (Brown, 2006) and "Kurtosis is a measure of the "tailedness"
0.8 , hence the dimensions used to assess this variable can be considered reliable.

of the probability distribution. A standard normal distribution has kurtosis of 3 and is recognized as mesokurtic. An increased kurtosis ( $>3$ ) can be visualized as a thin "bell" with a high peak whereas a decreased kurtosis corresponds to a broadening of the peak and "thickening" of the tails. Kurtosis $>3$ is recognized as leptokurtic and $<3$ as platykurtic (lepto=thin; platy=broad)" (Kallner, 2018). Therefore, it can be 
concluded that if the values of both skewness and kurtosis for each of our variables fall within the range of -3 to 3 , then they can be considered normal.

The Skewness of our independent variable of blogging is -0.216 which falls within the acceptable range. This value tells us that the distribution of $95 \%$ of the responses related to blogging are approximately symmetric around the mean value of 3.81. Similarly, the Kurtosis statistic for Blogging is 0.119 which is again in the acceptable range which implies that the curve for the responses is a normal bell-shaped curve.

For our second independent variable of reading, the Skewness Statistic is 0.825 which lies between the acceptable range of -3 to 3 and tells us that the $95 \%$ of the responses are moderately skewed in their distribution around the mean of 3.80. The Kurtosis Statistic for this variable is 0.876 , hence it is in the acceptable cohort, so it can be said that the responses have a normal bellshaped curve.

The Skewness statistic for the independent variable of writing is -0.817 lying in between the acceptable range and indicating moderate skewness in the distribution of $95 \%$ of the responses around the mean of 3.90. Also, the statistic for Kurtosis is 2.00 which is in the acceptable range and this value is greater than the Kurtosis statistic for the other independent variables. It implies that the height of the central peak of the bell-shaped curve is higher for the responses related to this variable of writing.

Considering our last independent variable of communication skills, the Skewness Statistic is - 0.554, falling within the acceptable range. Hence, the distribution of $95 \%$ of the responses are moderately skewed around the mean value of 3.81. The kurtosis statistic for this variable is 0.403 which is again in the acceptable range, indicating a normal, bell-shaped curve with a very small height of the central peak of the curve.

Lastly, our dependent variable of Academic Performance and Learning has a Skewness Statistic of -0.542 which is acceptable and indicates that $95 \%$ of the responses are distributed around the mean of 3.46. The Kurtosis statistic for this variable is 1.284 that lies within the acceptable range and represents a normal bell-shaped curve of the data gathered through the responses.

\section{LIMITATIONS AND CONCLUSION}

The research we conducted has certain limitations including the fact that we focused only on one university i.e., NUST and even in that university we distributed surveys to students of only departments. Hence, we might not have been able to gather diverse range of opinions and data on our topic. Also, our sample size was also quite small of 88 students, therefore for more accurate results the research would have to be extended to a bigger sample size.

\section{REFERENCES}

Applebee, A.N. \& Langer, J.A. (2006). The state of writing instruction in america's schools: what existing data tells us. Retrieved May 05, 2007, from http://cela.albany.edu

Aydin, S. (2014). The Use of Blogs in Learning English as a Foreign Language. Mevlana International 
Journal of Education (MIJE), 4(1),

pp.

244-259.

http://dx.doi.org/10.13054/

mije.13.79.4.1

Cho, H., Geri, G., Davidson, B., \& Ingraffea, A. (2007). Social networks, communication styles, and learning performance in a CSCL community. Computers \& Education, 49, 309329

Clark, C., \& Rumbold, K. (2006). Reading for pleasure: A research overview. Retrieved from http://files.eric.ed.gov/fulltext/ED 496343.pdf

Desi.Nur.Komariyah,(2015).Writing strategies used. http://repository.ump.ac.id/3199 /3/Bab\%20II Desi\%20Nur\%20Ko mariyah.pdf

Franklin T. Mobile learning: at the tipping point. TOJET - Turkish Online J. Educ.Technol. 2011;10(4):261.

Harb, Nasri and El-Shaarwi, Ahmed. (July 2006). 'Factors Affecting Students' Performance'. MPRA Paper No. 1362.

Hartley, J. (2007). Digital literacy and the active audience: Growing objective knowledge and creative imagination in post-broadcast media. In Proceedings of the Transforming Audiences Conference (pp. 1-12).

Hulin, C., Netemeyer, R., and Cudeck, R. (2001). Can a Reliability Coefficient Be Too High? Journal of Consumer Psychology, Vol. 10, Nr. 1, 55-58.

Kallner, A. K. (2018). Laboratory Statistics: Methods in Chemistry and Health Science, Second Edition. Laboratory Statistics
(Second Edition), 100. https://doi.org/10.1016/C2017-000959-X.

Khalidzuoud, \& Rawyaalshboul . (2018). The Effects of Communication Skills In Developing Preparatory Year Students' Performance.

https://www.worldresearchlibrary.org/ up proc/pdf/1657153751141341-42.pdf

Nailatul.Khasanah, (2015). Improving students' writing. http://repository.ump.ac.id/5266 /3/CHAPTER\%20II NAILATUL\%2 OKHASANAH BIOLOGI

\%2715.pdf

Puschmann, C. (2013). Blogging. Research gate.

Sellgren, K. (2013, September 11). Maths advantage for pupils who read for pleasure - BBC News. Retrieved from

http://www.bbc.com/news/educa tion-24046971

Stanley, G. (2013). Language Learning with Technology: Ideas for Integrating Technology in the Classroom. UK: Cambridge University Press.

Strauss, V. (2014, September 8). Why kids should choose their own books to read in school. The Washington Post. Retrieved from http://www.washingtonpost.com/ blogs/answersheet/wp/2014/09/ 08/why-kids-should-choose-theirown-books-to-read-in-school/

Tsinidou, M., Gerogiannis, V., \& Fitsilis, P. (2010). Evaluation of the factors that determine quality in higher education: an empirical study. Quality Assurance in Education, 
18(3), 227-244.

Waters, T. J., \& Marzano, R. J. (2006). School district leadership that works: The effect of superintendent leadership on student achievement. MidContinent Research for Education and Learning. Retrieved from ERIC
(ED494270).

Widdowson, H.G. (1975). The teaching of English as communication". In C.J. Brumfit \& K. Johnson (Eds.). The Communicative Approach to Language Teaching, (pp.15-18). London, Oxford University Press. 